... como terapia / as therapy

\title{
LA MÚSICA EN MUSICOTERAPIA
}

\author{
Patxi del Campo San Vicente \\ Musicoterapeuta, AMI felow, y especialista en Técnicas Grupales \\ Director del Instituto Música, Arte y Proceso
}

RESUMEN: La música es una forma de arte valorada a lo largo de toda nuestra vida. Este hecho, que puede ser disfrutado y valorado por personas de todas las edades, contribuye a su flexibilidad como herramienta terapéutica. Las experiencias musicales y las relaciones que se desarrollan a través de ellas, sirven como fuerzas dinámicas de cambio, posibilitando el proceso musicoterapeutico.

Palabras clave: Música, musicoterapia, lenguaje, comunicación y expresión.

\section{MUSIC IN MUSIC THERAPY}

ABSTRACT: Music is an art form appreciated at all moments in life. The fact that music can be enjoyed by people of all ages it makes it a very flexible therapeutic tool. Musical experiences and the relationships that are developed during them are dynamic sources of change and what make the music therapy process possible.

Keywords: Music, Music therapy, language, communication and expression.

\section{Distintas concepciones de música}

Cuando una persona está abierta, recibe a la música y se deja penetrar por ella, pasiva o gozosamente. Pero también la música recibe, contiene o es invadida por quien la necesita y sale a buscarla de manera activa. Entrar en la música es como entrar en el agua. La posibilidad de experimentar una sensación de bienestar depende tanto del grado de necesidad individual como de las temperaturas relativas de la persona y del agua. Cuando se siente calor, reconforta sumergirse en el agua fresca, pero si no se está 
acalorado ésta puede ser rechazante. Aun en el caso de una gran necesidad, el contraste excesivo de temperaturas podría resultar contraproducente (Hemsy de Gainza 1997, 99).

Cuando preguntamos ¿Qué es música?, la respuesta suele ser compleja, variada y llena de matices: armonía, expresión, sentimiento, alegría, plenitud, encuentro, y equilibrio.

La música se puede definir como "el arte de organizar los sonidos en el tiempo y sus variados componentes físicos y experimentales, para el propósito de crear e interpretar las formas expresivas que elaboran o dan significado a la experiencia de la vida humana".

La música, por su condición de "arte ambiental, para ser habitada, capaz de propiciar atmósfera, edificio sonoro sobre el aire"; arte ambiguo, por su "actividad edificante sobre el inexorable eje fluido del sucederse del tiempo", apreciaciones de Eugenio Trías (Trías 1991, 41); discurso sonoro que no tiene significado, lenguaje de lo inefable; arte fonético, espiritual y subjetivo, poseedor de una belleza más íntima que las artes plásticas.

Existen algunos principios fundamentales de la música que, aun siendo repetidamente comentados por muy conocidos libros de difusión musical, son generalmente olvidados por quienes Ilevan a la práctica las labores de acercamiento a la música. Por ello, me gustaría comentarlos brevemente:

1. La música es lenguaje del tiempo, es decir, nos aplica su tiempo a quienes la oímos. Es activa, fluyente, sin marcha atrás posible, discursiva y ordenada: su sentido nace por la ordenación de los sonidos. La música se ordena según un principio general de repetición, con tres ideas básicas de organización musical: la simetría, el contraste y la variación. De esta manera surge el ritmo, la melodía y las secuencias; todo ello es el fundamento de la forma de la música.

2. Nuestra memoria reproduce la forma, o sea, sigue los recorridos que dibujan los sonidos. El compositor puede sorprendernos, provocarnos, jugar con nosotros, pues nuestra misión como oyentes es la de relacionar unos con otros los momentos de la obra y seguir expectantes una dirección.

3. Nosotros no podemos explicar lo que quiere decir la música. Ella pregunta y responde sin que nosotros sepamos qué; accedemos a un nivel de entendimiento intuitivo y sensible, sólo su contenido está abierto a interpretación, ya que el significado de la música asoma por el juego que se establece entre sus elementos. El código de signos del que se sirve no nos expresa nada fuera de sí mismo, incluso tenemos la necesidad del conocimiento de dicho código, de su retórica y vocabulario si queremos comprender lo que nos expone. 
4. "La música no es pura pintura de sentimientos ni es tampoco pura forma, sino que es ambas cosas" (Hanslick 1947), cita Trías en su obra Lógica del limite. En efecto, la creación pura y llanamente formal de la música es prácticamente imposible, pues siempre hay un juego emocional, inseparable del acto de la creación. Del mismo modo, toda obra musical, por muy abstracta que sea, es susceptible de suscitar evocaciones poéticas o de imágenes por parte de un oyente imaginario. Nunca debemos olvidar que la música, arte y ciencia a la vez, es un tipo de expresión universal que nos habla íntimamente a cada uno de nosotros, y que su campo de expresión no conoce límite alguno: puede expresar tanto tragedia como serenidad, alegría o tristeza; esa expresión emotiva es transmitida por medio de símbolos que liberan la función auditiva, tanto emocional, como afectiva e intelectualmente. Yehudi Menuhin, ante la insistente pregunta: “Qué significa para usted la música que interpreta?", solía contestar: "La diferencia fundamental entre la música y el lenguaje hablado es que las palabras se refieren, ante todo, al mundo que nos rodea; la música, en cambio, se refiere especialmente a nuestro ser interior".

5. Hay músicas que se nos presentan a veces como una trama de ideas literarias y/o imágenes mentales, que se evocan o recuerdan por medio del sonido: son las descriptivas, o de programa (incluso hay compositores que bosquejan de antemano un plan emocional que sus oyentes deberán revivir). Otras son impresionistas o sugestivas: simplemente con un título pictórico o literario, definen un estado de ánimo (recordemos, por ejemplo que a Schumann se le ocurrían los títulos después de hacer cada una de las Escenas de niños).

La música goza de propiedades únicas para conmovernos tanto emotiva como físicamente, de filtrarse por lo más íntimo de nuestra razón, de asombrar a nuestro cerebro y abrir las puertas hacia la maquinaria que rige nuestros sentimientos y emociones. "El misterio del hombre tiene en la música su clave soterrada de sentido", nos dice Lévi-Strauss. "La música es nodriza de la lógica por su condición de pre-lenguaje" (Trías 1991, 42), comenta Trías. No cabe duda, para adentrarnos -y adentrar a nuestros alumnos- en el conocimiento de nosotros mismos y de los demás, en la comunicación con nuestros semejantes, en la apreciación del mundo y de sus manifestaciones, la escucha de la música juega un papel educativo de suma importancia que rebasa el objetivo musical para colocarse en el de las relaciones humanas.

Sin embargo no hay forma de definir qué es música, sin imponer algunos de los valores culturales implícitos en el lenguaje. Una característica notable de la música ha sido su capacidad de ser reconocida como medio terapéutico a lo largo de toda la historia occidental a pesar de los conceptos mutantes de salud y terapia. 


\section{Funciones de la música}

La música es una forma de arte valorada a lo largo de toda nuestra vida. Este hecho, que puede ser disfrutado y valorado por personas de todas las edades contribuye a su flexibilidad como herramienta terapéutica. Hay otras maneras en las que la música demuestra ser un arte flexible y utilizable.

\section{Expresión emocional y comunicación}

La música se ha asociado a menudo con la expresión emocional, incluso se le ha denominado "el idioma de las emociones". Así, como proveedor de emociones juega un importante papel en la sociedad, ya que proporciona un vehículo de expresión a las ideas y emociones que de otro modo no encontraran una forma de mostrarse fácilmente. Observemos por ejemplo casos de dolor y pérdida donde es muy difícil encontrar palabras adecuadas que expresen nuestros sentimientos más profundos. Si nos fijamos en las reivindicaciones sociales y movimientos culturales y sociales, observaremos como la música resulta una manera aceptable de expresar ideas que de otro modo hubiesen podido resultar polémicas o inaceptables.

Otro ejemplo que nos ilustra hasta que punto la música, como idioma no verbal, puede llevar a pensamientos o ideas podemos encontrarlo en las bandas sonoras de las películas y la televisión. Sus anuncios son otro ejemplo de cómo la música contribuye al significado del mensaje.

Podemos resumir diciendo que la música es una forma de comunicación no verbal que puede transmitir mensajes emocionales; influir o reflejar el estado de humor del oyente y puede usarse para intensificar, ampliar o modificar la información oral o visual de la situación observada o vivida.

¿Por qué se usa la música como expresión de emoción?

Nosotros trataremos de exponer aquí dos puntos de vista diferentes:

1. El sonido de la música nos recuerda o refleja emociones y acontecimientos no musicales. (Punto de vista referencial).

Este término refleja la creencia de que el significado que sé le dota a la música procede de las conexiones que el oyente hace entre la música y algún objeto y o acontecimiento.

a) Imitación de sucesos u objetos no musicales.

Podríamos encontrar numerosos ejemplos en la búsqueda de imitaciones de los sonidos de la naturaleza, pero también en otras características más estructurales de la música. Por ejemplo, la depresión es un sentimiento que produce expresiones faciales inclinadas, etc. Musicalmente podría reflejarse a través de tiempo lento, sonidos descendentes, etc. 
b) Asociación de canciones o estilos musicales a recuerdos y sentimientos de acontecimientos pasados.

Un ejemplo de esta situación pueden ser algunos himnos o canciones que evoquen los sentimientos de excitación y espíritu de equipo; la música chillona y discordante de los momentos cruciales de las películas de terror, etc.

2. Sin embargo a veces podemos dar una respuesta emocional a una música que no hemos oído antes.

Son las características estructurales de la propia música, como oposición a las asociaciones extramusicales, las que provocan sentimientos y emociones. (Punto de vista expresionista).

Según la teoría del psicólogo (Berlyne 1971) nuestros sentimientos serán, agradables si la música está en un nivel óptimo o ideal de complejidad o familiaridad.

Si la música presentada es demasiado compleja o poco familiar producirá en el oyente sentimientos de confusión, caos e incomodidad. Por el contrario si la música es demasiado simple o e ha oído muchas veces y le falta frescura el oyente puede sentirse aburrido e insatisfecho.

De cualquier forma desde el punto de vista musicoterapéutico también es importante considerar la música como un medio para crear una situación comunicativa donde existe un número infinito de posibles representaciones de la música.

\section{Representación simbólica}

Además de comunicar emociones, la música lleva significado simbólico. Los símbolos expresados con la música actúan diferente según el contexto cultural.

Así por ejemplo en la cultura occidental, la música se ha organizado alrededor de tonos y semitonos que constituyen escalas y modos. Frecuentemente hemos asociado el modo mayor con sentimientos felices, positivos mientras la música de tono menor tiene a menudo connotaciones de melancolía y tristeza.

Sin embargo la música de la India está organizada de intervalos más pequeños. Así si escuchamos la música tradicional india por primera vez la encontraremos difícil de organizar y entender según los parámetros de nuestra propia cultura. También nos costará interpretar los sentimientos emocionales expresados por ésta.

En resumen estos usos simbólicos convencionales de la música connotan un significado compartido para las personas con el mismo sustrato cultural y de este modo actúa eficazmente como canal de información. Cada cultura representará sentimientos, valores culturales u otros ideales abstractos a través de sus propios símbolos musicales. 


\section{Vehículo de expresión de normas e ideologías dominantes}

Cuando los terapeutas utilizan la música, es importante comprender que cada cultura y cada época tiene su propia herencia musical.

Frecuentemente la música, como soporte cultural, puede ayudar al individuo en su demanda por encontrar significado a su vida y para mejorar la calidad de la misma.

\section{Socialización}

La música es la más social de todas las artes, ha sido experiencia común de todos los tiempos. En si misma es una poderosa influencia integradora, aporta un sentimiento de orden, de tiempo y de continuidad, los sonidos que penetran dentro del grupo son percibidos por todos, creando un clima emocional.

La interacción social y la socialización es un objeto terapéutico en casi todos los órdenes y/o discapacidades, por lo que las experiencias musicales en grupo son utilizadas muy a menudo donde los elementos de ritmo, melodía y armonía requieren un nivel de orden y estructura creados por el propio grupo y donde, además es esta misma producción musical la que proporciona una válvula emocional al individuo y el grupo.

\section{Goce estético y diversión}

La música consta de ambos sentidos en todas las culturas y ambas funciones cumplen necesidades humanas importantes. Según E. Thayer Gaston (Gaston 1968), el envolvimiento en una experiencia musical que contenga un valor estético puede contribuir por si misma a la mejora de la autoestima y autorrealización.

De modo semejante Maslow (1972) sostiene que la experiencia estética es crucial para el desarrollo de la persona, pero siempre después de tener cubiertas las necesidades fisiológicas básicas.

Muchos terapeutas han reconocido que las personas con discapacidad necesitan y tienen derecho a participar en actividades estéticas como parte de la experiencia humana.

La música como diversión o recreativa también ocupa un lugar en la sociedad y de algún modo contribuye a un bienestar físico y emocional. Las personas buscamos actividades que nos liberen de la tensión de un día de trabajo difícil o para ayudarnos a despejar nuestra mente de los pequeños o grandes problemas cotidianos. La música, como forma de relajación contribuye a mejorar nuestro estado de salud físico y mental.

\section{Respuesta física}

El fenómeno físico de las vibraciones mecánicas (se dice que un cuerpo vibra cuando está realizando un movimiento oscilante respecto a una posición 
de referencia) es capaz de estimular en determinadas condiciones tres de nuestros receptores sensoriales: receptores propioceptivos, tacto y audición.

Si observamos el espectro de las oscilaciones y vibraciones mecánicas podemos esquematizar diciendo que los movimientos mas lentos escapan a nuestra percepción sensorial al igual que los más rápidos. Al ir aumentando la frecuencia de las oscilaciones, éstas pueden ser percibidas en principio por los receptores situados en las masas musculares (que nos informan de la tensión o fuerza que los mismos desarrollan para guardar el equilibrio postural), receptores propioceptivos que, junto con el aparato vestibular y la vista, constituyen la triada informativa de nuestra posición en el espacio. Si las oscilaciones aumentan de frecuencia, son ya los receptores táctiles los que nos dan cuenta de su presencia. Así en progresión creciente vemos cómo las vibraciones comienzan a producir sensación auditiva, sin abandonar el estímulo táctil simultáneo. Por fin, próximas a los $1000 \mathrm{~Hz}$ dejan ya de penetrar por el tacto y se hacen clara y exclusivamente auditivas, y por último, por encima de los $15.000 \mathrm{~Hz}$ sin cambiar nunca su naturaleza de oscilación mecánica, recibe la denominación de ultrasonidos, ya que nuestro receptor auditivo no es capaz de transformar su presencia en sensación.

Como la sensación auditiva y la táctil son de importancia básica en los procesos de rehabilitación, resulta inexcusable partir de una rica estimulación sensorial.

Trabajos realizados sobre el uso de la música de baja frecuencia han resultado eficaces para el alivio del dolor, espasmos musculares y de gran eficacia sobre el tejido pulmonar, que afloja las secreciones del pulmón en los pacientes con fibrosis cística, bronquietisis e infecciones del pecho, etc.

El organismo humano puede ser considerado como un instrumento resonante, lo mismo que como un instrumento rítmico, sensible a la música. Los instrumentos musicales que ha inventado el hombre son en esencia una prolongación de su propio cuerpo, manejados por sus impulsos físicos.

El cuerpo y el instrumento no son entes separados: se complementan. Esta característica permite al ejecutante identificarse físicamente con su instrumento mediante un contacto perceptual indispensable para crear una respuesta emocional. Cualquiera que sea la motivación emocional que lo acompañe el canto o la ejecución de un instrumento musical es un proceso físico. Requiere la aplicación de un dominio muscular y motor, y una apreciación espacial. Aún en los niveles inferiores, requiere alguna percepción auditiva y táctil sin la cual no constituye una válvula de descarga emocional.

\section{Uso de la música en musicoterapia}

Se dan algunos factores en terapia que no se encuentran en situaciones estrictamente musicales y que afectan al modo de definir y delimitar la música dentro de un encuadre musicoterapéutico. 
Las experiencias musicales y las relaciones que se desarrollan a través de ellas, sirven como fuerzas dinámicas de cambio.

El interprete tiene que estar atento a estas fuerzas y estas relaciones que se establecen observando y analizando los distintos planos: corporal, verbal, sonoro, social de cada individuo participante e identificar en el grupo a cada elemento, su estructura, las formas de interactuar en el mismo, así como las observaciones de los cambios y reacciones que se producen.

En una situación terapéutica la música se selecciona o se crea por su relevancia clínica, utilidad y atracción para la persona, y luego, de acuerdo a su mérito estético o artístico.

El musicoterapeuta tiene que llevar a la persona por una jerarquía de experiencias musicales, comenzando por una percepción de sus componentes sensomotores y gradualmente ir construyendo el aprecio de sus cualidades estéticas.

Los esfuerzos musicales de la persona atendida siempre se aceptan sin enjuiciarlos. Las actividades más comunes para el musicoterapeuta son recrear y crear.

Recrear música puede tener que ver con reproducir sonidos o frases musicales, representar sonoramente distintos paisajes musicales, y reproducir envolturas sonoras.

Crear música puede implicar hacer sonidos exploratorios, improvisaciones y composiciones.

La musicoterapia no es siempre solo música; a menudo se entremezcla con otras formas de arte. Muchas de estas formas de arte interrelacionadas se utilizan en musicoterapia: escribir canciones, contar una historia musical, dramatizaciones musicales, dibujos, etc.

En musicoterapia el proceso de resolver "problemas musicales" y las destrezas que se aprenden al encontrar resoluciones musicales sirven para generalizar hacia situaciones de vida. "Al improvisar música la persona trabaja sobre posibilidades de descubrimiento inventando nuevas opciones, eligiendo y contrastando alternativas, energetizando y proyectando esfuerzos en el tiempo y aunque estos esfuerzos tienen lugar dentro de un encuadre de trabajo musical se ven como una metáfora para lo que se necesita aprender o conseguir en la vida" (Bruscia 1987, p. 364).

Después de esta referencia a las funciones de la música es más fácil encuadrar los objetivos generales en musicoterapia:

1. Favorecer la comunicación. La música tanto si se escucha como si se ejecuta, favorece y posibilita un intercambio de ideas o sentimientos con otras personas.

2. Mejorar las relaciones interpersonales. Los sonidos que penetrar dentro del grupo son percibidos por todos, creando un clima emocional que permite expresarse y relacionarse con sinceridad, integridad y plenitud. 
Hacer música es una experiencia compartida que se desarrolla y se disfruta a partir del conocimiento de uno mismo y de su aptitud para comunicarse.

3. Desarrollar el conocimiento de uno mismo. Cuando la persona ejecuta o realiza alguna actividad instrumental, al margen de su capacidad, se desenvuelve en un mundo de acción positiva, adquiere medios técnicos de expresión, desarrolla relaciones personales sanas, se conduce de una forma social adecuada, etc.

Las actividades musicales pueden ayudarla a que adquiera o desarrolle conocimiento de sí mismo y de los demás y obtener experiencias gratificantes consigo mismo.

4. Desarrollar la capacidad de autoexpresión. La música que tiene el poder de evocar, asociar e integrar es un recurso excepcional de autoexpresión y liberación emocional.

El énfasis que se pone en que la música en terapia no se base en una noción idealista acerca del "poder curativo" de la música, sino que sus efectos terapéuticos son el resultado de una aplicación, profesional, metodológica o sistemática de la misma.

La musicoterapia se diferencia de la educación musical debido a su mayor preocupación por los aspectos del proceso de hacer música y también por focalizarse en los cambios personales del paciente / cliente como meta personal.

Desde la musicoterapia se considera que la enfermedad no sólo puede estar causada por el estado biológico o psicológico del paciente, sino frecuentemente por una falta de posibilidades de crecimiento y autorealización; A menudo las situaciones problemáticas obedecen a un conflicto de contradicción entre el estado psíquico o físico de la persona o el contexto socio-cultural que le rodea.

\section{Posibilidades de cambios dinámicos}

Para finalizar podemos afirmar que con el uso de música en terapia, musicoterapia, muchas personas mejoran considerablemente. En términos generales podríamos decir:

- La música como medio de expresión y de comunicación favorece el desarrollo emocional, mejora de un modo considerable las percepciones, la motricidad y la afectividad de la persona.

- La música favorece la manifestación de tensiones, problemas, inquietudes, miedos, bloqueos, etc. actuando como alivio y disminuyendo la ansiedad.

- La música suscita a la actividad, moviendo a la acción aceptada, que conlleva goce y satisfacción tanto a escala individual como grupal.

- Estimula nuestros receptores sensoriales propioceptivos, táctiles y auditivos. 
- Se consigue mayor equilibrio psicofísico y emocional. Consigue que se establezca una comunicación a través del arte y ésta es más inmediata y profunda que la palabra.

- Modifica algunas respuestas psicofisológicas que se registran en diferentes parámetros: ritmo cardíaco, amplitud respiratoria, reflejo psicogalvánico, etc.

- Fomenta la relación y socialización a través de la experimentación y ejecución conjunta.

\section{Bibliografía}

BERLYNE, D. E. (1971). Aesthetics and psychobiology. New York: AppletonCentury-Crofts.

BRUSCIA, K. (1987). Improvisational models of music therapy. Springfield, IL: Charles C. Thomas Publishers.

GASTON, E. T. et al. (1971). Tratado de musicoterapia. Buenos Aires: Paidos. HANSLICK, E. (1947). De lo bello en la música. Ricordi: Buenos Aires.

HEMSY DE GAINZA, V. (1997). Sonido, comunicación y terapia. Salamanca: Amarú.

MASLOW, A. (1972). El hombre autorrealizado. Barcelona: Kairós.

TRÍAS, E. (1991). Lógica del límite. Barcelona: Destino. 